\title{
O lugar da performance artística no museu: memórias, presenças e ausências
}

DANIELA SALAZAR

This paper addresses two main questions: What museum can we create through theatre practice? And, what kind of theatre practice do we have through the perspective of the museum? This critical analysis has as its starting point the relation between these two cultural instances: the Museum and Theatre (mainly its practice as an artistic discipline). The purpose of this paper is to define some lines and ways of reflecting on these curatorial processes, musealization, preservation and the institutionalization of the theatre memories and history. On the other hand, this paper aims to give also some new ways of thinking a new conception of the museum place based on the characteristics that define the theatre practice. This exercise of a critical analysis and also of a complementarity and opposition of two perspectives and different places will be the vehicle of presenting some case studies that will support its argument: A Living Museum of Small and Forgotten Memories, from Joana Craveiro (2014), The Curiosities' Cabinet, from Karnart (since 2012) and Alexandra do Carmo's work All was Captured (even the movements of the Goat) (Quadrum Gallery, 2011).

MUSEUM / THEATRE / MEMORIES / INSTITUTIONALIZATION / PRESENCE

The Louvre, The Louvre, Might it be that this museum is worth than all of France? Who needs France without the Louvre? Or Russia without Hermitage? Who would we be without museums! It sometimes seems museums don't care what happens around them as long as they're left in peace. Museums can also conceal the improper behavior of power and of people...

A. SOKUROV, Francofonia

O recente filme de Alexander Sokurov, Francofonia, num género entre o documentário e a ficção, relata-nos a tomada de Paris (e do Louvre!) pelas forças nazis alemãs. Numa reflexão irónica e romântica do poder do 
museu, considerei este um bom ponto de partida para reflectirmos os lugares das artes e da cultura.

O museu faz parte de um conjunto de estruturas culturais ocidentais e europeias que tem vindo a definir os padrões de legitimidade e credibilidade do conhecimento e das vivências culturais das populações desde o século XVIII. Surge nos imaginários das pessoas enquanto lugar da verdade, do conhecimento irrefutável e de elevação intelectual e cultural. Esta imagem tem representado aquele que é um dispositivo institucional que desempenha um conjunto variado de tarefas de selecção de objectos, narrativas e conteúdos que sejam representativos/simbólicos de um dado período histórico, da vida de alguém ou mesmo de uma prática cultural, social e/ou artística. A pertinência deste ensaio assenta justamente na análise crítica da relação que este dispositivo institucional estabelece com a prática teatral.

No que às classificações museológicas diz respeito, os museus dedicados à prática das artes performativas inserem-se na vasta categoria dos museus de arte (Rivière, 1989: 169). Não seria, logo desde o início, bom princípio caracterizar os museus de arte como portadores de uma mesma essência ou estrutura temática. Contudo, e apesar de em muitos aspectos se distanciarem, tem havido em alguns dos conceitos ou problemáticas uma proximidade entre a realidade museológica dos museus ligados às artes performativas e os museus de arte contemporânea. Essa proximidade está patente na tipologia de colecções que estes museus incorporam, ou seja, objectos e/ou documentação provenientes de práticas artísticas que implicam ou partem de uma apresentação performativa ou de uma relação performativa com esse mesmo objecto. Por outro lado, o museu é hoje um lugar em mudança, assente por sua vez, em grande medida, no conceito de performatividade e inserido na experience economy. ${ }^{1}$

No contexto desta tipologia museológica dedicada à prática das artes performativas, o próprio universo temático encerra algumas dificuldades na sua definição. Não só pela multiplicidade de práticas artísticas (até mesmo de origem mais tradicional, como são o caso do teatro ou da dança), mas também pela renovação conceptual do que é ou não considerada uma prática artística performativa, a definição deste campo torna-se complexa. É, de facto, exigente estabelecer critérios para o que

1 O conceito advém do seio da economia, mas tem sido progressivamente aplicado a outros contextos, tais como o social e cultural. Neste sentido, será de relevante consulta o artigo de Dorothea von Hantelmann «The Experiential Turn», na obra editada por Elizabeth Carpenter, Living Collections Catalogue, Walker Art Center, 2014. 
caracteriza uma obra enquanto performance artística e/ou performativa na sua componente de interacção com o visitante e da própria experiência que a obra poderá proporcionar.

Adrian George, no catálogo da exposição Art, Lies and Videotape Exposing Performance, que decorreu na Tate Liverpool em 2003, acentua, precisamente, esta dificuldade em definir o que é uma obra de performance artística ou de carácter performativo:

\begin{abstract}
"Dance", "theatre", "happenings", "performance" and many other names can be and have been applied to an entire spectrum of work by artists who have created live art events. An all-encompassing definition is almost impossible, but to put it at its simplest, live art contains a living element, a human presence - a body (or bodies) in space and at a specific moment, or for a definite period. However, it becomes very complicated when historians try to categorise and pigeonhole such a diversity of work. Take an installation that requires a human presence to activate or complete it could this be defined as a performance? If the work is staged, with a set and recognisable movements - is that theatre or dance or is it performance art? (George, 2003: 10)
\end{abstract}

Muitas seriam as problemáticas a reflectir e analisar num artigo submetido a esta temática; contudo, optei por centrar a minha perspectiva nos processos relacionados com a incorporação e institucionalização das memórias provenientes da prática teatral no contexto museológico, bem como discutir acerca de conceitos presentes no lugar destes museus, tais como presença, ausência, temporalidades, documentação e corpo. Impõem-se, no cerne, as questões: como pode o museu musealizar uma prática artística que logo após o final da sua apresentação é já memória de si própria? Como poderá um museu transmitir uma memória através de vestígios materiais dessa prática? Como podemos pensar o museu e o teatro enquanto lentes de observação um do outro?

PARTE 1 - INSTITUCIONALIZAÇÃO DE MEMÓRIAS: QUE TEATRO ENCONTRAMOS NO MUSEU?

O processo de criação de museus de teatro e dança nasce na Europa do século XIX. É em Moscovo, uma das cidades com maior importância para a História do teatro nos séculos XIX e xx, que Alexis Bakhruchine funda, em 1894, um museu de teatro privado, mas aberto ao público, 
constituído a partir da colecção de objectos teatrais que ao longo de vários anos foi reunindo. Em 1917 passa para a tutela do Estado, com a designação de Museu Central de Teatro Alexis Bakhruchine. Ainda na Rússia, é criado em 1918 o Museu Estatal do Teatro e da Música, em São Petersburgo. Na Alemanha a história de instituições dedicadas à preservação da memória do teatro e das artes do espectáculo data de 1902, com o surgimento da fundação da Sociedade de História do Teatro, depois transformada em Museu do Teatro de Berlim. Não existindo um museu nacional, outras cidades, como Munique (1910) ou Dusseldorf, dispõem de museus dedicados em exclusivo ao teatro. Em Viena encontra-se o Museu Austríaco de Teatro, criado em 1922 e actualmente instalado no centro histórico daquela cidade, no Palácio Lobkowitz. Por sua vez, o Museu do Teatro de Copenhaga (1912) está instalado num teatro setecentista integrado no Palácio Real. O Museu Nacional do Teatro de Espanha é, de todos, o mais recente, tendo sido inaugurado em 2002. Outros museus dignos de registo são o Dansmuseet (Suécia, 1953), a Colecção Suíça de Teatro (aberta ao público em 1944, em Berna), o Museu Nacional do Teatro da Finlândia (1962) e o Museu Nacional do Teatro da Eslovénia (1952). O Museu Nacional do Teatro e da Dança, na cidade de Lisboa, inicia a recolha do seu acervo e é inaugurado em 1985.

Apesar de não se institucionalizarem como museus, muitas colecções e acervos respeitantes ao teatro ou à dança estão integrados numa instituição com outra designação ou de âmbito mais alargado ou mais especializado. São exemplos disso o Departamento de Artes do Espectáculo da Biblioteca Nacional de França, a Biblioteca e Coleção Teatral del Bucardo, em Roma, e o Instituto de Teatro em Barcelona.

Como podemos verificar por esta curta genealogia do surgimento destes museus (pelo menos no que à realidade europeia concerne), esta não é uma tipologia museológica rara ou sem relevância no panorama museológico, artístico ou cultural destes países e, além do mais, revela que os museus desenvolvem uma missão de recolha, incorporação, investigação e divulgação destas práticas artísticas de grande destaque.

Pelo seu carácter intangível, quando da integração das peças provenientes destas mesmas práticas no museu, André Veinstein denomina estes mesmos objectos «vestígios» (Veinstein, 1992), denotando que pouco nos traziam da verdadeira dimensão ou do processo envolto nestas obras. As memórias que evocavam reforçavam, contudo, o seu valor enquanto objectos museológicos. Ainda assim, enquanto ferramentas de transmissão de memória no interior de uma instituição museológica, 
estes têm-se revelado pouco explorados. Para que possamos discernir sobre estes processos, é necessário relacionar, antes de mais, os próprios conceitos de memória, museu e performance artística.

Como primeira premissa para a análise destes conceitos, julgo ser importante referir o conceito de memória, não apenas enquanto conceito operativo, mas também enquanto processo. Neste sentido, Marita Sturken refere na sua obra o carácter fragmentário e múltiplo deste mesmo processo de memórias como a construção de várias narrativas, e não apenas de uma linha única (Sturken, 1997: 7).

Por sua vez, em Museums and Memory, Susan Crane destaca uma série de aspectos que considero essenciais como ponto de partida para a problematização da relação entre este conceito e a sua institucionalização no museu, bem como com o conceito de performance:

Memory is not a passive process; it evokes emotions and desires, positively or negatively charged; [...] By nature memory is mortal, linked to the brain and the body that bears it, as well as notoriously unreliable and subject to revision; if we would hold onto memory we must find some way to preserve it. Memory is not static, but it can be made to seem so through the creation of forms of representation that attempt to solidify memories' meanings, and it is through this realm of preservation that memories interact with museums. Memory is an act of "thinking of things in their absence". (Crane, 2000: 2)

A mortalidade «diagnosticada» por Susan Crane diz respeito, essencialmente, à componente humana donde todas as memórias são e serão provenientes, mas acima de tudo concerne às formas encontradas para a manter, nomeadamente na vertente que importa reter neste artigo, ou seja, em contexto institucional. Susan Crane problematiza, ainda, a questão da preservação museológica, referindo a forma como esta instituição selecciona o que merece ou não ser preservado ou/e que memórias poderão obter visibilidade (Crane, 2000: 3-9).

Em resposta ao ponto da não estaticidade da memória, o poder institucional museológico responde com a exposição, uma técnica que podemos considerar como forma de organizar um certo número de objectos, aos quais se pretende atribuir um significado conjunto e absoluto. Sobre este mesmo dispositivo, Mieke Bal descreve-o enquanto processo de visibilidade de um discurso assente nessa selecção de memórias que informam mas também afirmam uma posição e um significado (Bal, 1996), ideia que é reforçada, 
novamente, por Susan Crane que considera o acto de ser coleccionado como acto de atribuição de valor institucional (Crane, 2000: 2).

Estamos, assim, perante a problemática da institucionalização da memória. O processo de institucionalização da memória leva à construção de narrativas numa linha que não possibilita a interpelação, cristaliza-as, e é incorporada nos visitantes como sendo, assim, uma memória «extra-institucional». Ou seja, deturpa e retira o potencial de debate e interpretação/participação e partilha. Legitima o que o poder e as políticas - «the politics of remembering», como define Marita Sturken convencionam. Encontramo-nos, assim, perante a ideia de dispositivo agambeniano $^{2}$ - a memória é utilizada para legitimar essa função de informar «correctamente» e orientar perspectivas.

Regressemos à citação inicial de Susan Crane: é possível partir das componentes identificadas pela autora para estabelecer, desde já, uma ligação entre as próprias características da performance, como a sua (não) passividade, a sua mortalidade e a não estaticidade. Como podemos, facilmente, depreender de qualquer apresentação performativa, esteja esta inserida em contexto artístico ou social, ela é composta por uma natureza activa e interventiva, seja a nível físico, emocional, afectivo ou intelectual; desaparece assim que termina a sua apresentação e, mesmo que seja retomada com base num mesmo texto, coreografia ou ritual, a performance é sempre distinta da anterior; e, por último, retoma-se a ideia da performance como movimento, como oposto à ideia de imagem, ou seja, como prática que implica também uma reacção.

Na relação entre estas três instâncias (memória, museu, performance artística) e que, de alguma forma, não deixa de ser um processo próprio de toda a instituição museológica, está a capacidade de transmissão. Não me refiro apenas à transmissão de conhecimento, ou de informação visual referente aos objectos em exposição, mas ao processo de transmissão do invisível, ou seja, dessas memórias e estórias que ficam por trás dos documentos ou dos objectos. No que diz respeito aos museus de artes performativas, esse é um dos pilares essenciais para que a própria missão da instituição museal seja cumprida. Um museu que não se resuma à tal estaticidade do seu espaço, mas que seja um museu vivo.

2 Neste caso, dispositivo remete para a acepção foucaultiana e, depois, recuperada, em certo sentido, por Giorgio Agamben, de elemento de controlo e organização, seja este de informação ou dos corpos. Sobre esta temática, ver Michel Foucault, Surveiller et punir: naissance de la prison, Paris, Gallimard, 1975 [Vigiar e punir: nascimento da prisão, Lisboa, Edições 70, 2018]; ou Giorgio Agamben, Che cos'è un dispositivo?, Roma, Nottetempo, 2006. 
Acerca desta questão, é incontornável o contributo de Diana Taylor e dos conceitos que trabalhou de «arquivo» e «repertório». Deste modo, lidando com a noção de arquivo, a autora posiciona-se contra as dicotomias habituais entre memória e história, e assume os riscos dessa constante mutabilidade dos processos de memória, defendendo que a ideia de transmissão destas através da plataforma de arquivo perpetua as mesmas leituras e narrativas do poder. Abordando o conceito de repertório, Taylor argumenta no sentido em que este se verifica enquanto vertente de embodiment, de pluralidade de narrativas e de interpelação das histórias. Estas são assim duas plataformas em coexistência e que se deveriam complementar mutuamente (Taylor, 2003: 20).

No que concerne às artes performativas, quando o museu assume o papel de coleccionar e preservar as suas memórias, a exposição torna-se o palco dessas mesmas memórias. Neste contexto, destaca-se o debate sobre as estratégias curatoriais utilizadas nestes museus de forma a exporem o que resta de uma apresentação performática, realçando, aqui, a sua componente intangível como uma das suas principais características. Quando da identificação e reconhecimento dessas memórias, poderá a performance artística ser uma metodologia de as preservar e expor? Quero com isto introduzir, aqui, a possibilidade da integração da prática artística performativa como parte integrante da programação curatorial destes dispositivos institucionais, o que será preponderante para contrariar a tendência de cristalização das memórias que por elas são produzidas, mas também pelos espectadores e visitantes do museu.

Neste sentido, e ainda que fora do contexto institucional, gostaria de utilizar enquanto exemplo não só conceptual, mas também de prática artística, o projecto da autoria de Joana Craveiro, Um museu vivo de memórias pequenas e esquecidas, a que tive oportunidade de assistir/participar numa apresentação realizada em 2014, na Galeria Zé dos Bois, em Lisboa.

Um museu vivo... apresentou-se enquanto conferência-performance, mas também enquanto teatro documental, de forte cariz político. Joana Craveiro não desenvolve só um espectáculo, torna-o um dos elementos finais da sua própria investigação de doutoramento. ${ }^{3}$ Com formação

3 O tema que orientou o projecto de investigação de doutoramento de Joana Craveiro relaciona-se, precisamente, com a construção e performatividade das narrativas históricas e das memórias que compreenderam o período do início do Estado Novo até ao PREC (Processo Revolucionário em Curso), em Portugal. Poderá ser consultado sob a seguinte referência: Joana Craveiro, A Live/ /Living Museum of Small, Forgotten and Unwanted Memories - Performing Narratives, Testimonies and Archives of the Portuguese Dictatorship and Revolution, Londres, University of Roehampton, 2017. 
em Antropologia e Teatro, e centrada no período histórico português entre o Estado Novo e o PREC (Processo Revolucionário em Curso), Joana Craveiro recolhe histórias, testemunhos e memórias (muitas vezes acompanhadas de objectos que delas fizeram parte) não para nos contar uma, mas diversas histórias que caracterizam este mesmo período. A performance artística é aqui o meio eleito para a transmissão destas memórias, potenciando o seu carácter interpelativo e a possibilidade de as tornar elemento de reflexão (um pouco, talvez, à luz de Brecht, mas sem o distanciamento que este impunha). Neste projecto artístico, vemos, então, a junção destas mesmas três instâncias - o conceito de museu, memória e performance artística. Se é de fácil apreensão que a performance artística tenha sido o meio ideal para este processo de transmissão, revela-se mais subtil a utilização do conceito de Museu como elemento identificador do próprio espectáculo. Nesta perspectiva, num artigo da autoria da própria Joana Craveiro, esta refere:

Quando me propus construir um Museu e criei a persona Arquivista (a narradora/curadora/documentarista) deste Museu, usei conscientemente uma palavra que remete para o arquivo de Taylor, o museu: esse lugar de produção hegemónica de uma história oficial e sua apresentação/disseminação; e usei uma figura também de autoridade de conhecimento e mediação: a arquivista. Mas, por me propor construir um espectáculo teatral, assente nessa relação particular com o testemunho e com a participação do próprio público (em momentos-chave do espectáculo, assim como no debate final), aquilo que Um museu vivo opera é a interpelação do arquivo pelo repertório e vice-versa, é a própria transmutação do arquivo em repertório. (Craveiro, 2016: 44)

Permanece, assim, a ideia de um espaço aberto, de interpelações e de variadas interpretações do que se transmite. É esse espaço - o de um Museu Vivo - que no caso dos museus de artes performativas poderá ser construído a partir destas diversas formas de transmissão das memórias que da sua prática advêm.

PARTE 2 - PRESENÇAS E AUSÊNCIAS DO TEATRO PARA O MUSEU

Tal como o espaço performativo, lugar onde a performance artística decorre, também o espaço da exposição ou espaço curatorial é, por 
exemplo, identificado por Dorothea von Hantelmann como lugar de presenças: presenças materiais, de sentido e de temporalidades (Hantelmann, 2010: 10). Contudo, para que estas presenças se efectivem, outras darão lugar a ausências no processo, no qual este artigo se foca, da entrada da prática das artes performativas no museu. Este capítulo é justamente dedicado à relação entre as presenças e ausências do lugar da exposição destas práticas artísticas no museu.

Além destes factores relacionados com as presenças, Dorothea von Hantelmann defende o lugar da exposição como lugar de ritual, onde se realiza, também, uma acção que obedece a determinados regulamentos e a um guião de progressão: um lugar para a performatividade, onde a relação entre espaço e tempo se torna a base para a sua construção.

Ainda que fulcral no que a estas temáticas diz respeito, o conceito de presença, na sua relação com a performance artística e os conceitos de performatividade ou performativo, tem diversas perspectivas.

No que à prática destas artes diz respeito, Nick Kaye, na obra Archaeologies of Presence, indica algumas das principais características e interpretações deste mesmo conceito. A presença dos corpos, mas também o acto de estar em presença de alguém ou de algo, são variantes que orientam estas perspectivas: para o autor, presença implica interacção e testemunha (Kaye, 2012: 2). Define-a, também, enquanto experiência, estabelecendo, neste ponto, uma linha comum com a anterior citação de Dorothea von Hantelmann (que define o ritual da exposição enquanto potenciador do acto de encontro, de um encontro em presença[s]). Tal como no lugar da exposição, o próprio conceito de presença convoca, assim, sempre, um lugar de múltiplas relações, sejam estas temporais, materiais, intangíveis, corporais ou intelectuais.

O espaço curatorial de uma exposição acerca de artes performativas tem presente, em si, diversas dimensões temporais. Inclui, assim, o momento da performance artística, da sua recepção quando é apresentada, a subsequente produção e preservação de fragmentos que resultam da sua criação, bem como assume diferentes temporalidades nos registos que dela são realizados e, por último, do próprio momento em que todos estes elementos passam a fazer parte da memória do visitante. A acrescentar a estas variantes, a natureza do elemento «exposição» caracteriza-se pela sua longa duração, permanência e estaticidade, o que se opõe fortemente à duração de qualquer performance artística, devido à sua natureza efémera e circunscrita, assim como à interferência de factores externos, tais como a presença de um público. Na sua mais 
recente obra, Hal Foster denota, precisamente, esta variedade e multiplicidade de unidades temporais em presença, não só nas próprias obras de arte (neste caso mais orientadas para a arte contemporânea mas, como já foi referido, que estabelecem muitos pontos em comum com as restantes artes performativas) como no contexto curatorial em que estão inseridas:

Any artwork holds together various times of production and reception, not only as we confront it in the present of our own experience, but also as other moments are inscribed in the work as it passes through history. (Foster, 2015: 140)

É nesta lógica que deverá ser encarado o desafio curatorial referente à exposição destas manifestações artísticas, que são, ontologicamente, efémeras e intangíveis. É, nesta acepção, um exercício idêntico ao desenvolvido por Warburg: a desmontagem e remontagem das obras através dos seus fragmentos, dos seus vestígios, das suas memórias e das suas reproduções. ${ }^{4}$

No caso específico, por exemplo, do Museu Nacional do Teatro e da Dança, a tendência quando adquirem objectos respeitantes a uma determinada obra performática é a desmontagem e a descolagem das peças da obra de onde provém. Se os vestígios materiais advindos de uma qualquer peça de teatro, ao chegarem ao museu, integram colecções distintas, estes acabam por ser desligados do seu contexto original e são, posteriormente, apresentados no espaço expositivo como objectos isolados e dotados de uma qualquer qualidade estética ou técnica. Se tivéssemos de nos referir ao tempo em que estas nos são apresentadas, estaríamos perante um desafio anacrónico: a sua temporalidade, pelo facto de nelas coexistirem mais do que uma unidade de tempo, seria intangível e indefinível. Poderíamos, eventualmente, arriscar dizer que cada uma destas peças se encontra dentro de uma redoma atemporal. 
É, talvez, pertinente descrever os processos envolvidos nesta operação ou mesmo de que «vestígios materiais» estamos a falar. Ao passar pelo processo de desmontagem, o que resta destas performances artísticas advém de processos de documentação e recolha de materiais que compõem o espectáculo, desde textos teatrais, desenhos de coreografia, materiais de divulgação, figurinos, trajes de cena, fotografia e vídeo, entre outros. Ao separarem-se do seu contexto original (ou seja, do espectáculo ou performance artística em que estiveram presentes), estes objectos sofrem um processo de déplacement, o que lhes retira, igualmente, o seu valor enquanto objecto de conjunto, pertencente a uma obra, e lhes atribui um valor individual (fixado na qualidade de produção, técnica, autor, valor estético, entre outros). Tanto a fotografia quanto o vídeo surgem enquanto métodos mais eficazes de colocar em espaço curatorial «o fantasma» destas práticas artísticas. No entanto, entre diversos problemas que cada um levanta, ambos encontram o seu principal limite na ausência dos corpos. A presença fantasmática destes lugares exerce uma forte influência na sua definição e nas suas relações.

A consciência da ausência dos corpos daqueles que foram os actores e agentes directos das performances artísticas, agora objectos do espaço expositivo, advém, igualmente, de uma abordagem da preponderância que o corpo tem vindo a manifestar, nomeadamente no contexto do pós-modernismo. José Bragança de Miranda reforça justamente este argumento:

Se, nos dizeres de Walter Benjamin, o século XIX teve Paris por capital, e o século Xx a encontrou no cinema, agora a capital do nosso século será certamente o corpo. Há algo de estranho nesta constelação. Há maior evidência do que dizer que os «corpos» estiveram desde sempre presentes, por todo o lado, e também na pintura, na literatura, ou no cinema? A novidade está justamente na afirmação de que o corpo, depois de uma longa «repressão», se tornou uma questão prioritária nomeadamente na arte. (Miranda, 2004: 1)

Se assim foi na prática artística, também esta questão ganha relevância naquelas que são as instituições de arte, onde os museus se inserem. No caso dos museus de artes performativas, esta torna-se, de alguma forma, uma questão ambígua entre a ausência de um corpo passado (agente directo e activo da performance artística ao qual os vestígios em exposição dizem respeito) e a presença de corpos de passagem 
(de visitantes anónimos que se relacionam com os objectos e a sua materialidade, mas também com a intangibilidade destas ausências).

Entre estas presenças e ausências, gostaria de convocar dois casos de estudo de projectos artísticos que, na minha perspectiva, trazem algumas reflexões e considerações sobre a problemática geral deste artigo: o Gabinete de Curiosidades Karnart (desde 2012) e a obra Tudo foi captado (mesmo os movimentos do cabrito), de Alexandra do Carmo (Galeria Quadrum, 2011).

O projecto artístico Karnart - Criação e Produção de Objectos Artísticos Associação - tem a sua origem em 1996, quando Luís Castro, director artístico do projecto, ainda em Londres, cria uma obra, Comb, que não consegue classificar, no que diz respeito à sua tipologia.

Ao aproveitar um espaço de Smith's Galleries, no Covent Garden, em Londres, Luís Castro, juntamente com outros nove performers, alia, em colaboração, uma vertente de criação plástica, através da concepção de espaços site-specific e de instalação (que não funcionavam como cenário, mas como elementos activos e interventivos) com uma vertente de uma criação performativa, que bebia muito do (à época) tão acalentado teatro-dança. No entanto, no entender de Luís Castro, e perante a necessidade de anunciar o espectáculo, aglutina as palavras performance e instalação, de que resulta o conceito que tem trabalhado, o perfinst.

Nos últimos anos, desde 2012, a Karnart tem juntado às suas diversas problemáticas, de que são exemplo os direitos dos animais, as minorias sociais, questões de género, conflitos sociais e a cultura, a problemática do património e da memória das suas próprias criações. Nasce desta preocupação o Gabinete de Curiosidades (referência ao precursor dos primeiros museus de arte e ciência) onde a memória performativa dos objectos é tratada como um artefacto científico e como um elemento em permanente transformação, bem como fragmentado e numa lógica horizontal de relevância. Ao longo dos seus diversos espectáculos, a companhia e os seus criadores têm vindo a recolher objectos das suas pesquisas que, além de integrarem a narrativa do espectáculo em que «actuam», são reutilizados, não só numa lógica de ecologia material, mas de regresso e recuperação de memórias performativas. Guardam-nos, documentam-nos e, actualmente, expõem-nos como se de um Gabinete de Curiosidades se tratasse, devolvendo-os ao contexto performativo quando não só a sua componente material e física, mas igualmente as suas memórias, se tornam pertinentes numa nova criação. 
Todavia, deixa, igualmente, à solta a questão das ausências que se interligam com o próprio processo de memória: se, em tudo, se tenta preservar a memória destas criações através da constituição deste Gabinete de Curiosidades, em que cada objecto tem o seu lugar e a salvaguarda da sua memória performática, o que acontece ao corpo que não se pode arquivar e que será sempre um elemento externo de cada criação? Iremos sempre retornar à ausência de um dos principais agenciadores destas memórias, o próprio corpo, seja do performer ou do espectador, e que só poderá transmitir as suas próprias memórias quando convocado ao espaço performativo ou à reversibilidade do que poderá ser o espaço expositivo de um museu desta tipologia.

Por outro lado, na obra referida de Alexandra do Carmo ${ }^{5}$ Tudo foi captado (até os movimentos do cabrito) ${ }^{6}$, patente em exposição na Galeria Quadrum, em Lisboa, entre 24 de Setembro de 2011 e 22 de Janeiro de 2012, são, de certa forma, exploradas não só as componentes intangíveis destes processos de memória e do seu registo, bem como a imprevisibilidade das suas interpretações.

Num processo de recolha de memórias associadas à história da Galeria Quadrum e a alguns dos eventos e exposições que nela decorreram durante o período de direcção de Dulce d'Agro (1970-1980), a artista entra em contacto com e entrevista uma série de pessoas que assistiram a alguns desses eventos, nomeadamente a performances de Gina Pane ou João Vieira. As pessoas vão relatando o que viram e o que sentiram. Nestes relatos destaca-se, de facto, a variedade de interpretações sobre um mesmo evento, uma mesma performance artística. De um conjunto de pessoas que assistiram à performance de João Vieira, Caretos (1984) ${ }^{7}$, Alexandra do Carmo salienta a confusão entre a espécie animal que estava no espaço: se um cabrito ou um burro. ${ }^{8}$ Esta obra de Alexandra do Carmo, à qual adicionou a sua própria interpretação por meio da elaboração de uma série de desenhos, de carácter intensivo e serial, baseados

5 Alexandra do Carmo (n. 1966) é uma artista portuguesa. Estudou na Ar.Co em Lisboa, no Pratt Institute em Brooklyn e no Programa de Estudos Independentes do Whitney Museum, em Nova lorque. Fez parte de programas de residências artísticas no Location One em Nova lorque e no Irish Museum of Modern Art em Dublin. Expôs em diversos locais em Portugal, e internacionalmente nos Estados Unidos, Alemanha, Espanha e Irlanda. O seu trabalho está integrado em colecções públicas e privadas, tais como as do Irish Museum of Modern Art e da Fundação llídio Pinho, no Porto. É representada pela Galeria Carlos Carvalho, em Lisboa.

6 Para consulta de mais informações sobre a obra, http://www.alexandradocarmo.com/2011all-was-captured-even-the-movement-of-the-goat-/1.

7 O registo vídeo poderá ser consultado em http://quadrumarquivoparalelo.blogspot.pt/ search/label/1984.

8 Relato contado pela própria artista em conversa informal sobre o seu projecto artístico. 
nos dados recolhidos e trabalhados, traz à discussão e reforça o carácter fluido e moldável que este processo de memórias adquire por parte dos seus agentes, mas também a relevância que este trabalho de recolha de testemunhos orais atribui, posteriormente, à interpretação e transmissão destes processos.

\section{CONSIDERAÇÕES FINAIS}

O principal objectivo deste artigo compreende uma série de perspectivas e reflexões sobre um tema que está ainda por avaliar tanto no seio museológico como no da prática das artes performativas. As questões levantadas e os conceitos que apresentei são ainda o início de um longo trajecto a ser percorrido de forma colaborativa e em consciência das suas repercussões culturais, artísticas, mas também sociais e políticas. Os projectos artísticos referidos (aos quais poderiam ter sido acrescentados outros) são exemplos dessa consciência e da problematização destes temas por parte da prática artística, os quais poderão ser um forte contributo para pensar em contexto institucional.

\section{REFERÊNCIAS BIBLIOGRÁFICAS}

CRANE, Susan (2000), Museums and Memory, Stanford, Stanford University Press.

FOU CAUlt, Michel (1984), «Of Other Spaces: Utopias and Heterotopias», in Architecture/Mouvement/Continuité (Outubro).

KAYE, Nick, GIANNACHI, Gabriella e SHANKs, Michael (eds.) (2012), Archaeologies of Presence: Art, Performance and Persistence of Being, Londres/Nova Iorque, Routledge.

KENNEDy, Dennis (2009), The Spectator and the Spectacle: Audiences in Modernity and Postmodernity, Cambridge, Cambridge University Press.

SALAZAR, Daniela (2013), A performance artística e o espaço museológico - Os museus de artes performativas, dissertação de mestrado, Faculdade de Ciências Sociais e Humanas da Universidade Nova de Lisboa.

- (no prelo), «Montage as Curatorial Practice: Artistic Performance as an Object of Exhibition», in Revista História de Arte, Lisboa, Faculdade de Ciências Sociais e Humanas da Universidade Nova de Lisboa.

SCHNEIDER, Rebecca (2014), «Archives - Performance Remains», in Performance Research, Londres, Routledge.

TAYLOR, Diana (2003), The Archive and the Repertoire: Performing Cultural Memory in the Americas, Durham e Londres, Duke University Press.

VEINSTEIN, André (1992), La mise-en-scène théâtrale et sa condition esthétique, Paris, Libraire Théâtrale. 


\section{DANIELA SALAZAR}

Completou o mestrado em Museologia em 2013 na Faculdade de Ciências Sociais e Humanas da Universidade Nova de Lisboa e é desde 2015 doutoranda em Estudos Artísticos, na mesma faculdade, e bolseira da Fundação para a Ciência e Tecnologia. Foi responsável entre 2013 e 2014 pela programação do recém-criado Museu Sumol, tutelado pela Sumol+Compal, em Pombal. Foi investigadora no projecto da Associação para o Estudo do Teatro e do Espectáculo em Portugal, financiado pela Fundação Gulbenkian e coordenado pela Prof. Oliveira Barata (2012-2013). Estagiou em diversos museus, tais como o Museu Nacional de Arqueologia, o Museu Nacional da Música e o Museu Nacional do Teatro e da Dança (2010-2013). Actualmente, dedica-se ao projecto de doutoramento na área da curadoria de artes performativas em museus. 